\title{
ВИКОРИСТАННЯ ТЕХНОЛОГІЇ ОРЕКМР ДЛЯ РОЗРАХУНКУ ЕЛЕКТРОСТАТИЧНОГО ПОЛЯ СИСТЕМ ЕЛЕКТРОННОЇ ОПТИКИ
}

Проаналізовано особливості використання технології OpenMP у розпаралеленні розрахунку електростатичного поля для класів систем електронної оптики, граничні поверхні електродів яких володіють абелевою групою симетрії скінченного порядку. У процесі математичного моделювання потенціальних полів виникає необхідність розв'язувати системи лінійних алгебричних рівнянь великих розмірностей. Задачі розрахунку електростатичних полів вдається значно спростити шляхом максимального врахування наявної геометричної симетрії в конфігурації поверхонь електродів. Використання апарату теорії груп дає змогу забезпечити стійкість обчислень, створює усі передумови до розпаралелення процедур розв'язування складних тривимірних задач електростатики загалом. Таким способом зменшено обчислювальну складність у роз'язуванні систем лінійних алгебричних рівнянь, які апроксимують відповідні інтегральні. Для зменшення часу на обчислення запропоновано аплікацію методів математичного моделювання електростатичних полів із сучасними тенденціями розвитку комп'ютерної системи. Для реалізації паралельних алгоритмів використано мультиядерну архітектуру процесорів та таку властивість, як багатопотоковість. Оптимізація обчислювального процесу у розв'язуванні задач електронної оптики, що зумовлена бурхливим розвитком сучасних нанотехнологій та новими вимогами щодо швидкодії обчислень, реалізована 3 використанням технології паралельного програмування OpenMP. Проведено низку чисельних експериментів. Розглянуто класи систем із симетріями восьмого та шістнадцятого порядків. Використовуючи восьми- та шістнадцятиядерний процесори, шляхом варіації кількості паралельних потоків вдалось істотно зменшити час обчислень. Цим самим вдалось збільшити прискорення та ефективність паралельного алгоритму порівняно з послідовним. Підтверджено доцільність застосування пакету OpenMP для розпаралелення обчислень і вказано на можливість подальшої оптимізації програмного забезпечення для розв'язування класів задач зі симетріями скінченних порядків за критерієм мінімізації часу розрахунків за рахунок варіації кількості паралельних потоків та процесорних ядер комп'ютера.

Ключові слова: масові обчислення; мультиядерна система; математичне моделювання; система лінійних алгебричних рівнянь; абелева група.

Вступ. Зазвичай під час розв'язування практичних задач науки і техніки виникає проблема ефективної організації обчислень. Деякі задачі характеризуються необхідністю аналізу великих даних і прийняття рішень у режимі реального часу (Shakhovska, 2017). Зростання розмірності вхідних даних та масовість обчислень призводить до збільшення складності розв'язання задач. Тому потрібно вдосконалювати наявні підходи до організації та виконання обчислень і розробляти нові, використовуючи обчислювальні системи високої продуктивності.

Одним із способів оптимізації обчислювального процесу є його розпаралелення для подальшої реалізації на системах паралельної архітектури (Nemniugin \& Stesik, 2002). Залежно від алгоритму розв'язування задачі потрібно вирішувати проблему вибору обчислювальної системи для його реалізації. Так, для реалізації паралельних алгоритмів можна у паралельному режимі використовувати декілька комп'ютерів або звернутись до так званої багатопотоковості. Перший спосіб допомагає, обираючи різну кількість процесорів, досягати або максимальної ефективності їх завантаження, або ж збільшувати швидкість обчислень (Ilin, 1985). Другий спосіб дає змогу використовувати сучасні архітектури багатоядерних процесорів (Voss, 2003).

На сьогодні можливість покращення ефективності обчислювальної системи завдяки збільшенню тактової частоти процесора практично вичерпані або є економічно не вигідними. Перспективною є ідея підвищення продуктивності внаслідок збільшення кількості процесорів. Будування мультипроцесорних систем $є$ першим та найголовнішим напрямком у мультипотоковості, але для цього шляху розроблення потрібні великі кошти. Провідні виробники процесорів говорять про перспективний шлях розроблення комп'ютерів, який полягає у побудові комп'ютерних систем на основі мультиядерних процесорів. Тому використання мультиядерних систем є кращою можливістю для збільшення потужності процесорів. Багатоядерні обчислювальні системи дедалі ширше використовують у різних предметних областях і поступово витісняють одноядерні.

Важливим класом задач масових обчислень є задачі

\section{Інформація про авторів:}

Мочурад Леся Ігорівна, канд. техн. наук, асистент, кафедра систем штучного інтелекту. Email: lesiamochurad@gmail.com Бойко Наталя Іванівна, канд. екон. наук, доцент, кафедра систем штучного інтелекту. Email: nataliya.i.boyko@lpnu.ua Цитування за ДСТУ: Мочурад Л. І., Бойко Н. І. Використання технології ОрепМр для розрахунку електростатичного поля систем електронної оптики. Науковий вісник НЛТУ України. 2019, т. 29, № 3. С. 125-128.

Citation APA: Mochurad, L. I., \& Boyko, N. I. (2019). OpenMp technology application for calculating the electrostatic field of electronoptical systems. Scientific Bulletin of UNFU, 29(3), 125-128. https://doi.org/10.15421/40290326 
розрахунку потенціальних полів систем електронної оптики. Останні $є$ основними компонентами сучасних науково-дослідних комплексів, за допомогою яких вивчають складні фізичні процеси.

Мета дослідження - визначити особливості використання пакету OpenMP у розпаралеленні розрахунку електростатичних полів сучасних систем електронної оптики, що характеризуються наявністю симетрії в конфігурації поверхонь електродів.

Методи та об'єкт дослідження. В основу методології дослідження покладено метод інтегральних рівнянь у поєднанні з апаратом теорії груп і аплікація цих методів із сучасними тенденціями розвитку комп'ютерної техніки. Об'єктом дослідження стали класи систем із симетріями восьмого та шістнадцятого порядків.

Опис фізичної моделі досліджуваного явища. Електростатичне поле системи електронної оптики визначається системою $N$ безмежно тонких, ідеально провідних електродів $\left\{S_{i}\right\}$, які сукупно утворюють багатозв'язну поверхню $S:=\cup_{i=1}^{N} S_{i}$, де $S_{i} \cap S_{j}$ при $i \neq j$. До кожного електроду $S_{i} \in\left\{S_{i}\right\}$ прикладається відомий потенціал, який $є$ постійною величиною. Необхідно розрахувати розподіл потенціалу.

Можливість попереднього розрахунку електростатичного поля $є$ актуальною задачею під час проектування систем електронної оптики. IIÏ складність полягає у взаємодії між провідниками та перерозподілі заряду на їх поверхні. Визначення цього перерозподілу є ключовим етапом розрахунку результуючого електростатичного поля і визначає усю складність задачі: система рівнянь, яка описує розподіл заряду у системі заряджених провідників, має враховувати всі провідники без можливості зменшення їх кількості.

Опис математичної моделі досліджуваного явища. Під час математичного моделювання систем електронної оптики необхідно знайти функцію $u(P) \in H^{1}\left(\Omega_{s}^{-}, \Delta\right)$, яка задовольняє такі умови:

$$
\begin{gathered}
\Delta u=0 \text { в } \Omega_{s}^{-}:=\mathbf{R}^{3} \backslash \bar{S} ; \\
\delta^{ \pm} u=f(P) \text { на } S ; \\
\lim _{|P| \rightarrow \infty} u(P)=0, P \in \Omega_{s}^{-},
\end{gathered}
$$

де: $\delta^{ \pm}: H^{1}\left(\Omega_{s}^{-}\right) \rightarrow H^{1 / 2}(S)$ - оператори сліду, $f(P)(P \in S)$ - задане граничне значення потенціалу, яке на кожному 3 електродів $є$ постійним, а

$$
H^{1}\left(\Omega_{s}^{-}, \Delta\right):=\left\{u \mid u \in H^{1}\left(\Omega_{s}^{-}\right), \Delta u \in L_{2}\left(\Omega_{s}^{-}\right)\right\} .
$$

У загальному випадку ці постійні величини не володіють симетрією чи антисиметрією.

Відомо (Sybil, 1997), що задача (1)-(3) еквівалентна такому інтегральному рівнянню:

$$
\iint_{S} K(P, M) \rho(M) \mathrm{d} S_{M}=f(P), P \in S,
$$

де: $K(P, M):=1 / \operatorname{dist}(P, M)-$ фундаментальний розв'язок рівняння Лапласа в $\mathbf{R}^{3}$, а $\rho(M)$ - шукана густина розподілу зарядів на $s$.

Математичне моделювання електростатичних полів базується на визначенні поля заряджених електродів шляхом застосування чисельних методів до диференціальної (1)-(3) або інтегральної (4) форм рівняння, яка описує основну задачу електростатики. Чисельні мето- ди розв'язування інтегрального рівняння для гладкої граничної поверхні $s$ простої структури є добре відомими. Проте під час аналізу сучасних систем електронної оптики існує велика кількість заряджених електродів складної конфігурації. Використання при цьому навіть найекономнішого методу колокації за умов кусково постійної апроксимації шуканої густини розподілу зарядів вимагає чисельного розв'язування систем лінійних алгебричних рівнянь великих порядків 3 щільно заповненими матрицями. Це призводить до числової нестійкості. Оскільки більшість систем електронної оптики мають геометричну симетрію, то це дало підстави трактувати дане дослідження як задачу з абелевою групою симетрії скінченного порядку, що уможливило за тієї ж точності апроксимації істотно знизити порядок матричних рівнянь, які апроксимують відповідні IP i, таким способом, зменшило обсяг обчислень та розширило клас систем вказаного вигляду, допускаючи при цьому чисельне моделювання в межах методу граничних інтегральних рівнянь.

Розв'язування великих систем лінійних алгебричних рівнянь (СЛАР). Відшукання розв'язків великих СЛАР є однією з основних підзадач, які виникають у процесі математичного моделювання електростатичних полів шляхом застосування чисельних методів до диференціальної (1)-(3) або інтегральної (4) форми рівняння, яка описує основну задачу електростатики. На сьогодні під "велика" можна розуміти СЛАР, яка містить 1000 і більше невідомих. Кожен чисельний метод математичної фізики приводить до розв'язування СЛАР 3 матрицями певної структури.

Найефективнішим для розрахунку електростатичного поля систем електронної оптики є застосування методу інтегральних рівнянь (Mochurad \& Pukach, 2017a; Aksak et al., 2007). Під час аналізу сучасних систем електронної оптики помічено наявність великої кількості електродів складної конфігурації, тому використання цього методу приводить до розв'язування СЛАР великих розмірностей зі щільно заповненими матрицями. Внаслідок застосування методу Гаусса для чисельного розв'язування цих систем маємо виникнення нестійкості обчислень. Для класів систем електронної оптики, граничні поверхні електродів яких володіють абелевими групами симетрій скінченних порядків, вдається істотно знизити порядки матричних рівнянь, які апроксимують відповідні інтегральні (Mochurad \& Pukach, 2017b). I цим самим забезпечити стійкість обчислень. Врахування наявної симетрії в геометрії граничних поверхонь електродів шляхом застосування апарату теорії груп дає змогу від системи інтегральних рівнянь, де інтегрування ведеться по всій граничній поверхні перейти до еквівалентної послідовності незалежних інтегральних рівнянь, з інтегруванням тільки по деякій конгруентній складовій сукупної поверхні. Це створює усі передумови до розпаралелення розв'язування задачі загалом.

Паралельне програмування за технологісю OpenMP. Для подальшого розпаралелення обчислювального процесу розв'язування незалежних інтегральних рівнянь ефективним є використання програмного засобу паралельного програмування зі специфікацією OpenMP (Antonov, 2009; Balandin \& Shurina, 2000). Розпаралелення розрахунку електростатичного поля для класу системи електронної оптики, граничні поверхні 
електродів якої володіють абелевою групою симетрії деякого $N$-го скінченного порядку, полягає у тому, що розв'язування незалежних рівнянь виділяється в окремі потоки та запускається паралельно. Ця задача виконується псевдокоментарями стандарту OpenMP. Теоретично достатньо перевести послідовне розв'язування $N$ інтегральних рівнянь у мультипотокове, якщо у рівнянь немає залежностей, як і $є$ у нашому випадку. Псевдокоментарі ділять послідовність інтегральних рівнянь на паралельні блоки автоматично та передають кожний 3 них відповідному ядру процесора. При цьому не потрібно описувати обмін інформацією. Наприклад,

\#pragma omp parallel num_threads ( $\mathrm{n}$ )

\{

// Даний код буде виконуватись $n$ потоками

\# pragma omp for

//Частини циклу будуть поділені між $n$ потоками основноі групи потоків

$\cdots$

Для отримання значень часу обчислень можна використати такий фрагмент:

-...

// Запам'ятовуємо початковий час

DWORD dwStart =::GetTickCount();

// Виконуємо паралельні обчислення

Calculate();

// Обчислюємо час виконання

m_dwRunTime $=::$ GetTickCount ()$-$ dwStart.

Результати організації паралельних обчислень. Відомо (Balandin \& Shurina, 2000), що метод Гаусса вимагає $2 / 3 n^{3}+\mathrm{O}\left(n^{2}\right), n \rightarrow \infty$ арифметичних операцій, де $n$ - розмірність СЛАР. Для досягнення високої точності обчислень при розрахунку електростатичного поля деякого класу систем електронної оптики необхідно збільшувати кількість точок колокації, відповідно зростатиме розмірність СЛАР. Застосування теорії груп дає змогу зменшити обчислювальну складність при роз'язуванні СЛАР у $N^{2}$, де $N$ - порядок групи симетрії, якою володіє конфігурація поверхонь електродів відповідної системи електронної оптики.

Для проведення чисельних експериментів у роботі розглянуто класи систем зі симетріями восьмого $(N=8)$ та шістнадцятого $(N=16)$ порядків. На рис. 1 та 2 подано залежність часу обчислень під кількості потоків при реалізації паралельних обчислень щодо розв'язування послідовності восьми та шістнадцяти незалежних інтегральних рівнянь на восьми- та шістнадцятиядерному процесорах, відповідно. Розмірність СЛАР $-n=500$, точність обчислень $\varepsilon=0,01$.

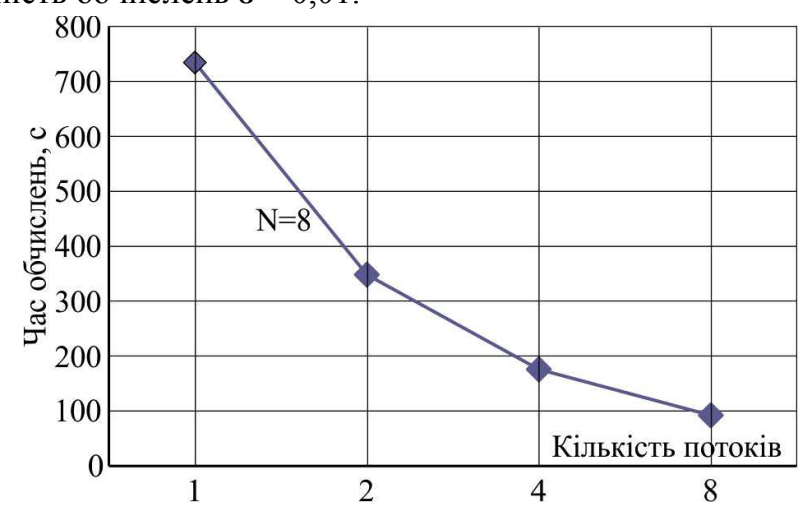

Рис. 1. Залежність часу обчислень від кількості потоків на восьмиядерному процесорі

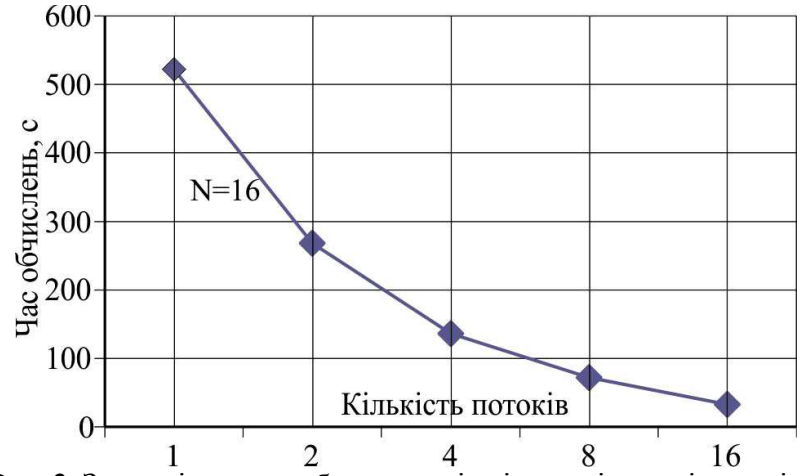

Рис. 2. Залежність часу обчислень від кількості потоків на шістнадцятиядерному процесорі

Отже, шляхом використання сучасної архітектури багатоядерних процесорів вдалось істотно зменшити час обчислень у розв'язуванні СЛАР, що апроксимують відповідні послідовності незалежних інтегральних рівнянь. Для класів систем зі симетріями восьмого та шістнадцятого порядків - приблизно у 8 та 16 разів, відповідно. Отримані результати вказують на можливість подальшої оптимізації програмного забезпечення шляхом варіації кількості паралельних потоків та ядер процесора. Співвідношення кількості послідовно до кількості паралельно виконуваних операцій призвело до зростання потужності у 8 та 16 разів, відповідно.

Висновки. Для оптимізації обчислювального процесу розрахунку електростатичного поля сучасних систем електронної оптики було взято до уваги, що застосування апарату теорії груп до класів систем, поверхні електродів яких володіють абелевою групою симетрії того чи іншого скінченного порядку, створює усі передумови до розпаралелення розрахунку електростатичних полів. 3 огляду на стрімкий розвиток багатоядерної архітектури у роботі запропоновано аплікацію методів математичного моделювання полів систем електронної оптики із сучасними тенденціями розвитку комп'ютерної техніки. Знайдено співвідношення кількості послідовно до кількості паралельно виконуваних операцій, що призвело до зростання потужності у програмуванні у $N$ - разів, де $N$ - порядок групи симетрії, якою володіє конфігурація поверхонь електродів відповідної системи електронної оптики. Внаслідок цього вдалось зменшити час обчислень при розв'язуванні СЛАР, які апроксимують відповідні інтегральні рівняння приблизно у $N$ разів за умови, що кількість рівнянь збігається з кількістю ядер процесора, за різної варіації паралельних потоків.

\section{Перелік використаних джерел}

Aksak, N. H., Volontsevych, V. D., Osotov, I. A., \& Filin, Ya. M. (2007). Doslidzhennia zbilshennia potuzhnosti u prohramuvanni na multyiadernii klasternii systemi. Bulletin of the National University "Lviv Polytechnic", 603, 8-11. [In Ukrainian].

Antonov, A. S. (2009). Parallelnoe programmirovanie s ispolzovaniem tekhnologii OpenMP. Moscow: Moscow State University Publishing House. [In Russian].

Balandin, M. Yu, \& Shurina, E. P. (2000). Metody resheniia SLAU bolshoi razmernosti. Novosibirsk: Izd-vo NGTU. [In Russian].

Ilin, V. P. (1985). Chislennye metody resheniia zadach elektrofiziki. Moscow: Nauka. Glavnaia redaktciia fiziko-matematicheskoi literaturi, 340 p. [In Russian].

Mochurad, L. I. (2019). Metod reduktsii modeli dlia rozrakhunku elektrostatychnykh poliv system elektronnoi optyky. Radio electronics, computer science, management: scientific journal, 1(48), 2940. [In Ukrainian]. 
Mochurad, L. I., \& Pukach, P. Ya. (2017b). Aposteriornyi metod otsiniuvannia pokhybky i rozparalelennia obchyslen dlia odnoho klasu zadach elektronnoi optyky linzy. Scientific Bulletin of UNFU, 27(5), 155-159. [In Ukrainian].

Mochurad, L. I., \& Pukach, P. Ya. (2017a). Efektyvnyi pidkhid do rozrakhunku elektrostatychnoho polia kvadrupolnoi linzy. (Vol. 1). Bulletin of the Kherson National Technical University, 3(62), 155165. [In Ukrainian].

Nemniugin, S. A., \& Stesik, O. L. (2002). Parallelnoe programmirovanie dlia mnogoprotcessornykh vychislitelnykh sistem. St. Petersburg: BKhV-Peterburg, 256 p. [In Russian].
Shakhovska, N. (2017, September). The method of Big data processing. In Computer Sciences and Information Technologies (CSIT): $12^{\text {th }}$ International Scientific and Technical Conference (Vol. 1), (pp. 122-126).

Sybil, Yu. M. (1997). Three Dimensional Elliptic Boundary Value Problems for an Open Lipschitz Surface. Math. Studios, 8(2), 79-96.

Voss, M. J. (2003). OpenMP share memory parallel programming. Toronto, Kanada.

\author{
L. I. Mochurad, N. I. Boyko
}

Lviv Polytechnic National University, Lviv, Ukraine

\title{
OPENMP TECHNOLOGY APPLICATION FOR CALCULATING THE ELECTROSTATIC FIELD OF ELECTRON-OPTICAL SYSTEMS
}

The article presents the analysis of the features of the use of one of the OpenMP technology in the parallelization of calculating the electrostatic field of the classes of modern electron-optical systems, the boundary surfaces of electrodes of which have an abelian finite-order symmetry group. In the mathematical modeling process of potential fields, it is necessary to solve systems of linear algebraic equations of large dimensions. The tasks of calculating electrostatic fields can be greatly simplified by maximizing the geometric symmetry within the configuration of the electrode surfaces. The usage of the group theory technique allows ensuring the stability of the calculations, creates all the prerequisites for parallelizing the procedures for solving complex three-dimensional problems concerning electrostatics in general. The application of the mathematical modeling methods of electrostatic fields along with the modern trends within the computer system development has been considered in order to reduce the calculation time. For realization of parallel algorithms the multi-core architecture of processors and such property as multithreading are used. A number of numerical experiments were conducted. The classes of systems with symmetries of the eighth and sixteenth orders are considered. Using an eight-core and sixteen-core processor, by varying the number of parallel streams, it was possible to significantly reduce the computational time. Thus, it was possible to increase the acceleration and efficiency of the parallel algorithm in comparison with the successive. The expediency of using the OpenMP package for calculating parallelization has been confirmed and indicated for the possibility of further optimization of the software for solving problem classes with finite-order symmetries based on the criterion for minimizing settlement time due to the variation in the number of parallel streams and processor cores of the computer. The optimisation of the computational process in solving electron-optics tasks due to the rapid development of modern nanotechnology and new requirements for the speed of calculations has been implemented using the OpenMP parallel programming technology. The classes of systems with symmetries of the eighth and sixteenth orders have been considered. Using an eight-core and sixteen-core processor by varying the number of parallel streams, it was possible to significantly reduce the computational time.

Keywords: mass calculations; multi-core system; mathematical modeling; system of linear algebraic equations; abelian group. 